\title{
Comment on "Danshen and the Cardiovascular System: New Advances for an Old Remedy"
}

\author{
Bradley J. McEwen, PhD, MHSc ${ }^{1}$ \\ ${ }^{1}$ Department of Nutritional Medicine, Endeavour College of Natural \\ Health, Sydney, New South Wales, Australia \\ Semin Thromb Hemost 2016;42:323-324.
}

Address for correspondence Bradley J. McEwen, PhD, MHSc, Department of Nutritional Medicine, Endeavour College of Natural Health, 815-825 George Street Sydney, New South Wales 2000, Australia (e-mail: Brad.McEwen@endeavour.edu.au).
Cardiovascular disease (CVD) is the leading cause of mortality worldwide. ${ }^{1}$ CVD is multifactorial with risk factors including platelet hyperaggregation, ${ }^{2}$ increased coagulation factor activity, decreased fibrinolytic capacity, ${ }^{3}$ dyslipidemia, diabetes, overweight/obesity, physical inactivity, nutrition, and a family history of CVD. ${ }^{1}$

It has been previously reported that diet (e.g., the Mediterranean diet), foods (e.g., berries, chocolate, garlic, tomato), ${ }^{4}$ nutrients (e.g., omega- 3 ), ${ }^{4,5}$ and herbal medicines $^{6}$ alter platelet function. Herbal medicines in particular have a long history of use and have numerous actions, including antiplatelet, anti-inflammatory, hemostatic, antioxidant, cholesterol lowering, antispasmodic, expectorant, and immunomodulatory properties. ${ }^{6}$

Danshen (Salvia miltiorrhiza) is a traditional Chinese herbal medicine that has been used for the treatment of various CVDs, such as coronary heart disease, acute myocardial infarction, hyperlipidemia, and cerebrovascular disease. ${ }^{6}$ Studies have shown significantly increased prothrombin time when Danshen was coadministered with warfarin. ${ }^{6}$ In their recent correspondence with this journal, Maione and Mascolo discuss the beneficial cardiovascular effects of Danshen, particularly on platelet function. ${ }^{7}$ They discuss the effects of the bioactive diterpenoid quinones, tanshinone IIA (TIIA) and cryptotanshinone (CRY). Previously, the authors showed that TIIA selectively inhibited in vitro platelet aggregation induced by reversible adenosine diphosphate (ADP) $(3 \mu \mathrm{M})$ stimuli on rat platelets but was less active against the irreversible stimuli induced by ADP $(10 \mu \mathrm{M})$ and collagen $(10 \mu \mathrm{g} / \mathrm{mL})$. In a mouse model study, the authors showed that the intraperitoneal injection of TIIA significantly prolonged bleeding time. ${ }^{8}$ The authors also previously showed that cryptotanshinone inhibited platelet aggregation in a rat model and also showed that cryptotanshinone was a P2Y12 receptor antagonist. ${ }^{9}$ From their findings, Maione and Mascolo provide an understanding of the biological properties of TIIA and CRY and their effects on platelet function in animal models. Although Maione and Mascolo highlight the potential use of Danshen in the management of cardiovascular disease, further research of Danshen and that of the bioactive diterpenoid quinones TIIA and CRY is suggested on human platelets and in human clinical trials with and without antiplatelet and anticoagulant drugs to further investigate their mechanisms of action.

Herbal medicines are commonly used by patients alongside standard medical therapy. Herbal medicines have the potential to interact with medications, such as aspirin, clopidogrel, and warfarin ${ }^{6}$ and may be prescribed together with conventional therapies. However, for the management of CVDs, it is suggested that herbal medicines are best prescribed by practitioners qualified in herbal medicine or by physicians with training in herbal medicine for patients taking antiplatelet or anticoagulation drugs, following a consultation based on the results of in-depth clinical history/case taking.

In conclusion, herbal medicines can play a beneficial role in the management of CVD. Further research in humans is suggested to investigate the effects of Danshen and other herbal medicines on platelet aggregation/function and coagulation, in addition to their effects on the various other risk factors of CVD, such as atherosclerosis, hypercholesterolemia, and hypertriglyceridemia.

\section{Conflict of Interest}

There is no conflict of interest to declare.

\section{References}

1 Mozaffarian D, Benjamin EJ, Go AS, et al; American Heart Association Statistics Committee and Stroke Statistics Subcommittee. Heart disease and stroke statistics-2015 update: a report from the American Heart Association. Circulation 2015;131(4):e29-e322

2 Ruggeri ZM. Platelets in atherothrombosis. Nat Med 2002;8(11): $1227-1234$
Issue Theme Platelet Function in Thrombosis and Hemostasis; Guest Editor: Anne-Mette Hvas, MD, PhD.
Copyright $\odot 2016$ by Thieme Medical Publishers, Inc., 333 Seventh Avenue, New York, NY 10001, USA. Tel: +1(212) 584-4662.
DOI http://dx.doi.org/ 10.1055/s-0036-1580087. ISSN 0094-6176. 
3 Koenig W. Haemostatic risk factors for cardiovascular diseases. Eur Heart J 1998;19(Suppl C):C39-C43

4 McEwen BJ. The influence of diet and nutrients on platelet function. Semin Thromb Hemost 2014;40(2):214-226

5 McEwen BJ, Morel-Kopp MC, Chen W, Tofler GH, Ward CM. Effects of omega-3 polyunsaturated fatty acids on platelet function in healthy subjects and subjects with cardiovascular disease. Semin Thromb Hemost 2013;39(1):25-32

6 McEwen BJ. The influence of herbal medicine on platelet function and coagulation: a narrative review. Semin Thromb Hemost 2015; 41(3):300-314
7 Maione F, Mascolo N. Danshen and the cardiovascular system: new advances for an old remedy. Semin Thromb Hemost 2016;42(3): 321-322

8 Maione F, De Feo V, Caiazzo E, De Martino L, Cicala C, Mascolo N. Tanshinone IIA, a major component of Salvia milthorriza Bunge, inhibits platelet activation via Erk-2 signaling pathway. J Ethnopharmacol 2014;155(2):1236-1242

9 Maione F, Cantone V, Chini MG, De Feo V, Mascolo N, Bifulco G. Molecular mechanism of tanshinone IIA and cryptotanshinone in platelet anti-aggregating effects: an integrated study of pharmacology and computational analysis. Fitoterapia 2015;100:174-178 